\title{
Snoring and hypertension: a 10 year follow-up
}

\author{
E. Lindberg*, C. Janson*, T. Gislason**, K. Svärdsudd+, J. Hetta++, G. Boman*
}

Snoring and hypertension: a 10 year follow-up. E. Lindberg, C. Janson, T. Gislason, K. Svärdsudd, J. Hetta, G. Boman. CERS Journals Ltd 1998.

ABSTRACT: In many cross-sectional studies an association has been found between snoring and hypertension. However, differing results have been obtained when confounding factors have been taken into account.

To establish whether snoring is a risk factor for developing hypertension, a population-based, prospective survey was performed. In 1984 and 1994, 2,668 males, aged 30-69 yrs at baseline, answered questionnaires concerning sleep disturbances and somatic disease.

Of the habitual snorers in $1984,12.5 \%$ reported that they had developed hypertension during the period, compared with $7.4 \%$ of the remaining subjects $(p<0.001)$. In a multiple logistic regression model persistent snoring, i.e., reported habitual snoring in both 1984 and 1994, was found to be an independent predictor for the development of hypertension among males aged 30-49 yrs (odds ratio $2.6,95 \%$ confidence interval 1.5-4.5) after adjustments for age, body mass index (BMI), weight gain, smoking, alcohol dependence, and physical inactivity. Among the subjects aged 50-69 yrs in 1984, no association between snoring and development of hypertension was found.

Although based only on reported data, the results indicate that persistent snoring is an independent risk factor for the development of hypertension among males aged $<50$ yrs. Prospective surveys, including whole-night sleep recordings, are needed to establish whether this is due to a higher prevalence of obstructive sleep apnoea syndrome among snorers or whether nonapnoeic snorers with increased upper airway resistance also have an increased risk of developing hypertension. Eur Respir J 1998; 11: 884-889.
*Dept of Lung Medicine and Asthma Research Centre, Uppsala University, Akademiska sjukhuset, Uppsala, Sweden. **Dept of Lung Medicine, Viffilsstadir Hospital, Gardabær, Iceland. +Dept of Family Medicine, and ${ }^{+}$Sleep Disorder Unit, Dept of Psychiatry, Uppsala University, Akademiska sjukhuset, Uppsala, Sweden.

Correspondence: E. Lindberg

Dept of Lung Medicine

Akademiska sjukbuset

S-751 85 Uppsala

Sweden

Fax: 4618662819

Keywords: epidemiology

hypertension

prospective

sleep disorders

snoring

Received: April 301997

Accepted after revision November 211997

This study was supported financially be the Swedish Heart and Lung Foundation, The Swedish Medical Research Council and The Uppsala Association Against Heart and Lung Disease.
A number of surveys have addressed the issue of whether there is an association between snoring and hypertension. In many studies a significantly higher prevalence of hypertension has been found among habitual snorers than among nonsnoring individuals [1-4]. However, snoring and hypertension have many risk factors in common. Cross-sectional and case-control studies have shown that snoring is associated with: obesity; age; smoking; heavy alcohol consumption; and physical inactivity [5-9]. After adjustments for these confounding factors, it was found in several recent studies that hypertension was not significantly associated with snoring [9-11]. In two review articles the authors have stated that there is no epidemiological evidence of a causal relationship between snoring and hypertension and one of the points they have criticized is the lack of prospective surveys within this field [12, 13].

To investigate whether habitual snoring is a risk factor for developing hypertension, a prospective, populationbased study was carried out with an observation period of $10 \mathrm{yrs}$.

\section{Materials and methods}

\section{Population and study design}

The study population has been described in detail elsewhere [3, 14]. In short: in 1984, 4,021 males, aged 30-69 yrs, from the municipality of Uppsala, Sweden, were randomly selected for this epidemiological survey. A postal questionnaire was sent to all subjects, with a response rate of $79.6 \%$. Of the 3,201 subjects who replied in 1984, 226 had died by October 1994. A new questionnaire was sent to the remaining 2,975 in November 1994. After two reminders, questionnaires that had been answered acceptably were returned by 2,668 subjects $(89.7 \%)$.

\section{Questionnaires}

The questionnaire used in 1984 comprised 24 questions concerning somatic diseases, snoring and other sleep disturbances. A description of this questionnaire has been published previously $[3,14]$. In the question about snoring, the subjects were asked to state the frequency of "loud and disturbing snoring", using a five-point scale. In the subsequent statistical evaluation, those subjects with scores of 1 (never), 2 (seldom) and 3 (sometimes) were regarded as nonhabitual snorers and those with scores of 4 (often) and 5 (very often) as habitual snorers. The terms persistent nonsnorers and persistent snorers were used to characterize those subjects who were in the same category in both 1984 and 1994. Questions were asked about body weight, height and body mass index (BMI, in $\mathrm{kg} \cdot \mathrm{m}^{-2}$ ) was calculated. The change in BMI $(\triangle \mathrm{BMI})$ was calculated as BMI 1994-BMI 1984. 
The subjects were classified as hypertensive if they reported attending regular medical check-ups for hypertension and/or answered "yes" to the question "Do you have high blood pressure?".

In the questionnaire used in 1994, the first part was identical to that used in 1984. In the second part, 45 new questions were added, including questions about current and past smoking habits, alcohol use and physical activity.

The smoking status was investigated by asking the subjects if they had ever smoked regularly for at least 6 months and if they were current smokers or exsmokers. Current and exsmokers were asked at what age they had started smoking and how many cigarettes per day or grams of tobacco per week they smoked. Exsmokers were also asked in which year they had stopped smoking. From the answers it was established whether or not the subject had been a smoker in 1984.

Heavy alcohol use was investigated by the cut down, annoyed by criticism, guilty about drinking, eye-opener drinks (CAGE) questionnaire [15, 16], which has been found to be highly sensitive and specific for the recognition of alcohol dependence, as defined by the Diagnostic and Statistical Manual of Mental Disorders (DSM-III) [16]. When translated into Swedish, one of the questions was slightly modified to fit the Swedish conditions more effectively. The questions used were: "Have you ever felt you should cut down on your drinking?", "Have you ever annoyed people by your drinking?", "Have you ever felt guilty about your drinking?" and "Have you ever taken a drink in the morning to get rid of a hangover ('eyeopener')?". Alcohol dependence was defined as positive answers to at least two of the four questions.

To estimate the level of physical activity, four different categories with an increasing level of physical activity during leisure time were presented [17]. In the following analyses, physical inactivity was defined as category 1 i.e., spending most time in front of the television, reading, and other sedentary activities. Category 2 involved riding a bicycle to work, walking, fishing or bowling, for example, for at least $4 \mathrm{~h}$ a week. Categories 3 and 4 involved participation in more vigorous activities on a weekly basis. The subjects were asked to place themselves into one of these categories.

The definition of hypertension was the same as in 1984. Subjects reporting hypertension in 1994 but not in 1984 were classified as "new hypertensives".
The informed consent of all participants was obtained and the study was approved by the Ethics Committee of the Medical Faculty at Uppsala University.

\section{Statistical analysis}

Statistical analysis was performed on a Macintosh IIci computer (Apple Computer Inc., Cupertino, CA, USA) using the Statistica 4.0 software package (StatSoft Inc, Tulsa, OK, USA). The results are presented as mean \pm SD. For comparison of proportions, a chi-square test was used. When the comparison involved continuous variables, the Mann-Whitney U-test was used, while the Spearman Rank correlation test was used to calculate correlations between continuous variables. For simultaneous evaluation of more than two variables, multiple logistic regression analysis was performed and the results are presented as adjusted odds ratios (OR) and $95 \%$ confidence intervals (95\% CI).

\section{Results}

Of the 2,668 subjects, $2,622(98.3 \%)$ had answered the question about snoring in 1984. Of these, $393(15.0 \%)$ reported habitual snoring. The characteristics of the participants and the groups with different snoring status in 1984 are presented in table 1.

From the answers given in 1994, the smoking habits in 1984 could be calculated for 2,553 men $(95.7 \%)$. The questions about alcohol and physical activity were answered by $96.0 \%$ and $98.4 \%$, respectively. BMI in 1984 could be calculated for $99.6 \%$ and $\Delta \mathrm{BMI}$ for $97.8 \%$ of subjects.

The age distribution of the responders in 1984 was almost the same as in the target population [3, 14]. In 1994, the 312 nonresponders were somewhat younger than the responders (mean age 53.7 \pm 11.6 versus $55.1 \pm 11.1$ yrs, $\mathrm{p}=0.002$ ) but did not differ significantly in terms of the mean BMI in 1984 (24.6 \pm 3.1 versus $24.4 \pm 2.9, \mathrm{p}=0.4)$, the prevalence of habitual snoring in 1984 (17.9\% versus $15.0 \%$, $\mathrm{p}=0.2)$ or hypertension in $1984(10.2 \%$ versus $8.1 \%, \mathrm{p}=$ $0.4)$.

In 1984, hypertension was reported by 217 of the 2,668 men $(8.1 \%)$, more frequently by habitual snorers. On average, the habitual snorers were older, more often obese

Table 1. - Characteristics of the participants in 1994, total and by snoring status in 1984

\begin{tabular}{|c|c|c|c|c|}
\hline & \multirow[t]{2}{*}{ Total } & \multicolumn{3}{|c|}{ Snoring category $1984^{*}$} \\
\hline & & Nonhabitual & Habitual & p-value ${ }^{\dagger}$ \\
\hline Participants $\mathrm{n} \%$ & 2668 & $2229(85.0)$ & $393(15.0)$ & \\
\hline Age 1984 yrs & $45.1 \pm 11.1$ & $44.7 \pm 11.2$ & $47.0 \pm 10.3$ & $<0.001$ \\
\hline BMI $1984 \mathrm{~kg} \cdot \mathrm{m}^{-2}$ & $24.4 \pm 2.9$ & $24.2 \pm 2.8$ & $25.5 \pm 3.0$ & $<0.001$ \\
\hline BMI Š27 n \% & $435(16.4)$ & $328(14.8)$ & $102(26.1)$ & $<0.001$ \\
\hline$\Delta \mathrm{BMI} \mathrm{kg} \cdot \mathrm{m}^{-2}$ & $0.9 \pm 1.8$ & $1.0 \pm 1.8$ & $0.5 \pm 2.0$ & $<0.001$ \\
\hline Smokers 1984 n \% & $856(33.5)$ & $676(31.6)$ & $164(44.3)$ & $<0.001$ \\
\hline Physical inactivity 1994 n \% & $410(15.6)$ & $342(15.6)$ & $62(16.1)$ & NS \\
\hline Alcohol dependence 1994 n \% & $256(10.0)$ & $218(10.2)$ & $34 \quad(9.0)$ & NS \\
\hline Hypertension $1984 \mathrm{n} \%$ & $217 \quad(8.1)$ & $162(7.3)$ & $51(13.0)$ & $<0.001$ \\
\hline "New hypertension" 1994 n \% & $218 \quad(8.2)$ & $164 \quad(7.4)$ & $49(12.5)$ & $<0.001$ \\
\hline
\end{tabular}

Values are presented as absolute number, or mean \pm SD, with percentages in parentheses. *: forty six subjects did not answer the question concerning snoring in 1984; $\div$ : habitual versus nonhabitual snorers; $;$ : percentages of the subjects who answered the questions concerning the respective category; BMI: body mass index; $\triangle$ BMI: BMI 1994-1984; Ns: nonsignificant. 
and more frequently current smokers, whereas their weight gain during the $10 \mathrm{yr}$ period was lower than that of the nonhabitual snorers (table 1). Ten years later, the number of hypertensive subjects was 392 (14.7\%). In the whole group, 218 subjects $(8.2 \%)$ reported hypertension in 1994 but not in 1984 and were, thus, classified as "new hypertensives".

Of the habitual snorers in 1984, $12.5 \%$ (49 of 393) had developed "new hypertension", compared with 7.4\% (164 of 2,229) of the nonhabitual snorers $(\mathrm{p}<0.001)$ (table 1). In the whole population univariate analysis showed significant associations between "new hypertension" and age $(\mathrm{r}=0.06, \mathrm{p}=0.002)$, BMI $1984 \quad(\mathrm{r}=0.13, \mathrm{p}<0.001)$ and $\triangle \mathrm{BMI}(\mathrm{r}=0.04, \mathrm{p}=0.03)$. After adjustments for age, "new hypertension" was also associated with alcohol dependence (OR 1.6, 95\% CI 1.01-2.4) and physical inactivity (OR 1.6, 95\% CI 1.04-2.6).

Among the males without hypertension in 1984, a significantly higher prevalence of "new hypertension" was found among habitual snorers even after dividing the population on the basis of BMI, $\triangle \mathrm{BMI}$, smoking, alcohol dependence and physical inactivity (fig. 1). When the population was subgrouped according to age, however, the higher prevalence of "new hypertension" was found only among habitual snorers in the lower age group.

To analyse the independent influence of risk factors on the development of hypertension, multiple logistic regression analyses including all subjects that did not report hypertension in 1984 were performed $(n=2,451)$. Complete data, (i.e., no missing data in any of the eight variables in the model), were available for 2,127 males (86.8\%). In the whole group, persistent snoring was independently associated with "new hypertension" after adjustments for age, BMI, $\triangle \mathrm{BMI}$, smoking, physical inactivity and alcohol dependence, with an adjusted OR of 1.8 (95\% CI 1.1-3.0). Besides age, independent predictors for "new hypertension" were BMI Š27 $\mathrm{kg} \cdot \mathrm{m}^{-2}$ (OR 2.2, 95\% CI 1.5-3.2) and $\triangle \mathrm{BMI}$ (OR 1.15, 95\% CI 1.05-1.3).

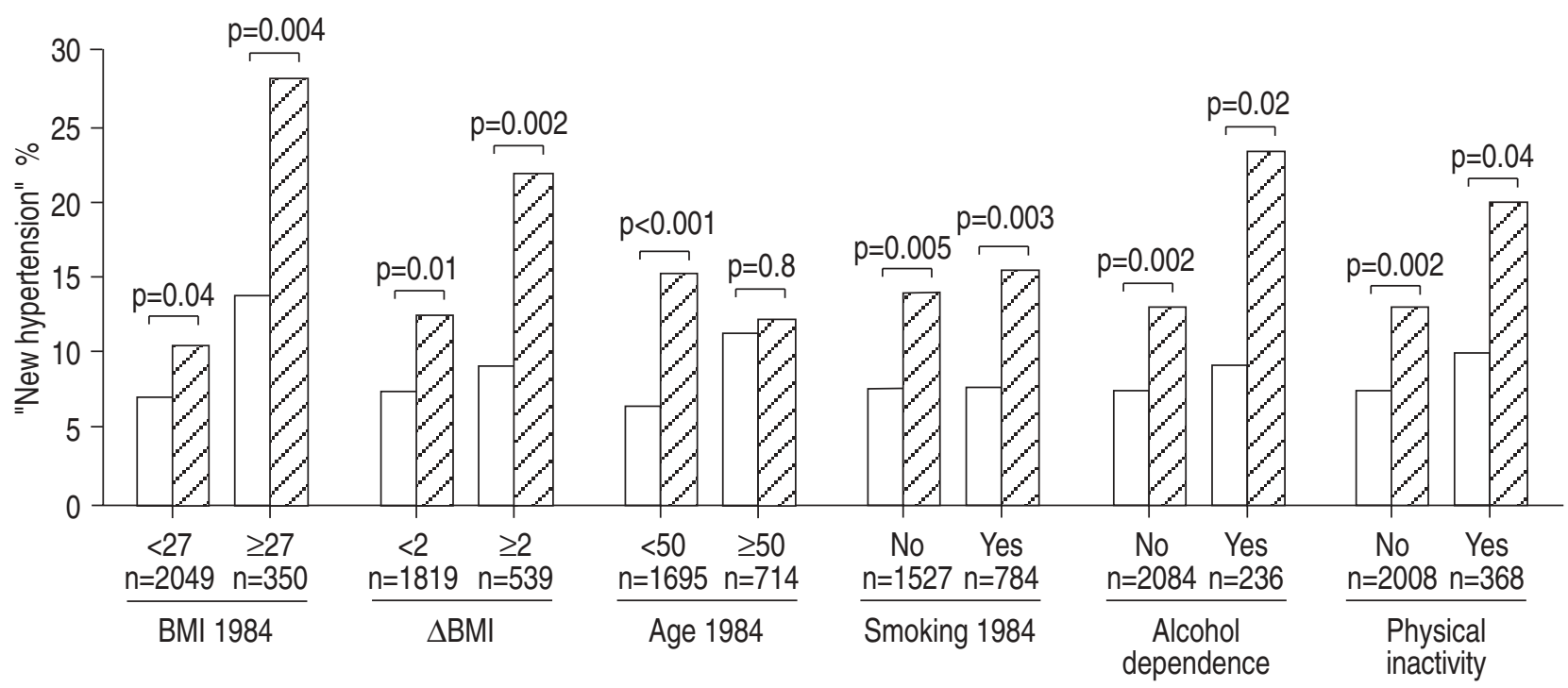

Fig. 1. - Incidence of "new hypertension" during the $10 \mathrm{yr}$ period (hypertension reported in 1994 but not in 1984) in subjects with nonhabitual snoring $(\square)$ and habitual snoring $(\square)$ in 1984 . The p-values were calculated for differences between snoring categories within each subgroup. BMI: body mass index measured in $\mathrm{kg} \cdot \mathrm{m}^{-2} ; \Delta$ BMI: BMI 1994-BMI 1984.

Table 2. - Risks of developing hypertension during a $10 \mathrm{yr}$ period among males aged 30-49 yrs in 1984 without hypertension in that year $(n=1,718)$

\begin{tabular}{|c|c|c|c|c|c|}
\hline Independent variable & \multicolumn{2}{|c|}{$\begin{array}{l}\text { No hypertension } \\
1994(\mathrm{n}=1,585)\end{array}$} & \multirow[t]{2}{*}{$\begin{array}{c}\text { "New hypertension" } \\
1994(\mathrm{n}=133)\end{array}$} & \multirow[t]{2}{*}{$\begin{array}{c}\text { OR univariate } \\
\text { analysis }\end{array}$} & \multirow[t]{2}{*}{$\begin{array}{c}\text { OR multivariate } \\
\text { analysis* }\end{array}$} \\
\hline Reported snoring & & & & & \\
\hline Persistent nonsnoring & 1134 & (73.8) & $76(58.5)$ & 1.0 & 1.0 \\
\hline Nonhabitual snoring 1984, habitual snoring in 1994 & 220 & (14.3) & $20(15.4)$ & $1.4(0.8-2.3)$ & $1.4(0.8-2.3)$ \\
\hline Habitual snoring 1984, nonhabitual snoring 1994 & 64 & $(4.2)$ & $12(9.2)$ & $2.8(1.4-5.4)$ & $2.0(0.96-4.3)$ \\
\hline Persistent snoring & 118 & $(7.7)$ & $22(16.9)$ & $2.8(1.7-4.6)$ & $2.6(1.5-4.5)$ \\
\hline \multicolumn{6}{|l|}{ Age 1984} \\
\hline $30-39$ yrs & 972 & (61.3) & $62(46.6)$ & 1.0 & 1.0 \\
\hline $40-49$ yrs & 613 & (38.7) & $71(53.4)$ & $1.8(1.3-2.6)$ & $1.7(1.1-2.5)$ \\
\hline BMI Š27 kg.m-2 1984 & 159 & $(10.1)$ & $36(27.1)$ & $3.3(2.2-5.0)$ & $2.7(1.7-4.4)$ \\
\hline$\Delta \mathrm{BMI} \mathrm{kg} \cdot \mathrm{m}^{-2}$ & 1.2 & $(1.1-1.3)^{+}$ & $1.5(1.2-1.7)^{+}$ & $1.1(0.98-1.2)$ & $1.1(1.01-1.3)$ \\
\hline Smoking 1984 & 545 & $(35.2)$ & $46(36.2)$ & $1.0(0.7-1.5)$ & $0.9(0.6-1.3)$ \\
\hline Alcohol dependence 1994 & 187 & (12.0) & 19 (14.7) & $1.3(0.8-2.1)$ & $1.3(0.7-2.3)$ \\
\hline Physical inactivity 1994 & 272 & $(17.3)$ & $31(23.7)$ & $1.9(1.1-3.3)$ & $1.4(0.8-2.6)$ \\
\hline
\end{tabular}

*: the independent variables were examined in a multiple logistic regression model with "new hypertension" as the dependent variable. Values are presented as the number of subjects, and percentages in parentheses, except where indicated. The results are presented as odds ratios (OR) with 95\% confidence intrevals (95\% CI). +: mean and 95\% CI. BMI: body mass index; $\triangle$ BMI: BMI 1994-BMI 1984. 
Table 3. - Risks of developing hypertension during a $10 \mathrm{yr}$ period among males aged 50-69 yrs in 1984 without hypertension in that year $(n=733)$

\begin{tabular}{|c|c|c|c|c|}
\hline Independent variable & $\begin{array}{l}\text { No hypertension } \\
1994(\mathrm{n}=648)\end{array}$ & $\begin{array}{c}\text { "New hypertension" } \\
1994(\mathrm{n}=85)\end{array}$ & $\begin{array}{c}\text { OR univariate } \\
\text { analysis }\end{array}$ & $\begin{array}{l}\text { OR multivariate } \\
\text { analysis* }\end{array}$ \\
\hline \multicolumn{5}{|l|}{ Reported snoring } \\
\hline Persistent nonsnoring & $468(76.7)$ & $55(70.5)$ & 1.0 & 1.0 \\
\hline Nonhabitual snoring 1984, habitual snoring in 1994 & $39 \quad(6.4)$ & $8(10.3)$ & $1.8(0.8-3.9)$ & $1.0(0.4-2.7)$ \\
\hline Habitual snoring 1984, nonhabitual snoring 1994 & $59 \quad(9.7)$ & $10(12.8)$ & $1.4(0.7-3.0)$ & $1.3(0.6-3.1)$ \\
\hline Persistent snoring & $44 \quad(7.2)$ & $5 \quad(6.4)$ & $1.0(0.4-2.5)$ & $0.8(0.2-2.2)$ \\
\hline \multicolumn{5}{|l|}{ Age 1984} \\
\hline $50-59$ yrs & $354(54.6)$ & $53(62.4)$ & 1.0 & 1.0 \\
\hline $60-69$ yrs & $294(45.4)$ & $32(37.6)$ & $0.7(0.5-1.2)$ & $0.7(0.4-1.2)$ \\
\hline BMI Š27 kg·m²- 1984 & $134(20.8)$ & $25(29.4)$ & $1.6(0.96-2.6)$ & $1.6(0.9-2.9)$ \\
\hline$\Delta \mathrm{BMI} \mathrm{kg} \cdot \mathrm{m}^{-2}$ & $0.2(0.1-0.3)^{+}$ & $0.7(0.3-1.2)^{+}$ & $1.2(1.04-1.4)$ & $1.2(1.03-1.4)$ \\
\hline Smoking 1984 & $177(29.8)$ & $30(37.0)$ & $1.4(0.9-2.3)$ & $1.2(0.7-2.1)$ \\
\hline Alcohol dependence 1994 & $26(4.4)$ & $8(10.1)$ & $2.5(1.1-5.7)$ & $1.9(0.7-5.2)$ \\
\hline Physical inactivity 1994 & (9.3) & $12(14.8)$ & $1.5(0.6-3.6)$ & $1.7(0.6-4.4)$ \\
\hline
\end{tabular}

*: the independent variables were examined in a multiple logistic regression model with "new hypertension" as the dependent variable. Values are presented as the number of subjects, and percentages in parentheses, except where indicated. The results are presented as odds ratios (OR) with $95 \%$ confidence intervals $(95 \% \mathrm{CI})$. +: mean and 95\% CI. BMI: body mass index; $\Delta$ : change in BMI 1994-BMI 1984.

As there was no significant increase in the prevalence of "new hypertension" among habitual snorers in the older age group (fig. 1), we also performed a multiple logistic regression analysis for the younger (30-49 yrs in 1984) and older (50-69 yrs in 1984) age groups separately (tables 2 and 3). In this model, habitual snoring was associated with hypertension only in the younger population. Compared with the persistent nonsnorers of ages 3049 yrs in 1984, the persistent snorers in that age group showed an increased risk of developing hypertension, with an adjusted OR of 2.6 (95\% CI 1.5-4.5). The habitual snorers in 1984 who became nonhabitual snorers during this $10 \mathrm{yr}$ period also showed a tendency to an increased risk of developing hypertension (adjusted OR 2.0, 95\% CI 0.96-4.3). The other independent predictors of hypertension in the younger age group were age, BMI 1984 S $27 \mathrm{~kg} \cdot \mathrm{m}^{-2}$ and $\Delta$ BMI. In the older age group, the only variable that was significantly associated with hypertension after adjustment for the other variables in the model was $\triangle \mathrm{BMI}$ (table 3 ).

Limiting the definition of "new hypertension" to subjects on antihypertensive medication $(n=146,5.5 \%)$ did not change the results of the multivariate analysis to a major degree. Among subjects aged 30-49 yrs, the adjusted OR for persistent snoring was 2.2 (95\% CI 1.034.6), while there was still no association between snoring and "new hypertension" in the older age group.

\section{Discussion}

The results of our study indicate that among males of ages 30-49 yrs, habitual snorers who continue to be heavy snorers run an increased risk of developing hypertension within the next decade. This increased risk was found to be independent of obesity at onset, weight gain, age, smoking, alcohol dependence and physical inactivity.

As far as we know, this is the first prospective survey in which the association between snoring and hypertension has been studied. In an earlier cross-sectional survey, we found an association between snoring and hypertension and in the age group 40-49 years this was significant even after adjustments for age and BMI [3]. This is in accordance with the findings of Koskenvuo et al. [1] in an investigation of Finnish males and females aged 40-69 yrs [1]. In contrast, StRAdLING and Crosby [10] found no significant increase in the prevalence of hypertension among snorers after adjustments for age and BMI. Similarly, in the surveys by Jennum and SృøL [11] and Koskenvuo et al. [9] the association between snoring and hypertension was no longer significant after adjustments for confounders.

One of the strengths of this investigation is the fact that the response rate after 10 yrs was high (almost 90\%) and that the questions relating to hypertension were identical in 1984 and 1994. The Swedish population in general is familiar with the disorder hypertension and the reliability of answers regarding this diagnosis in a questionnaire is good. In 1984 the prevalence of reported hypertension came close to prevalence data on hypertension in Sweden [3]. There are no actual prevalence data on hypertension for Sweden in 1994. However, in an epidemiological study in Göteborg, Sweden in 1993, which included recording of the medical history and physical examination of $50 \mathrm{yr}$ old males, the prevalence of treated hypertensives was $6.4 \%$ [18]. The corresponding prevalence in the age group 45-55 yrs in the present population was $6.6 \%$, indicating that the validity of reported hypertension is good.

One disadvantage of this study is the fact that questions relating to alcohol and physical activity were only included in the 1994 questionnaire. It might be argued that the answers are not reliable when applied to 1984, leading to a decrease in the reliability of the measurements. However, the questions relating to alcohol consumption are formulated as "Have you ever", and, therefore, also involve the past. Despite this, no association was found between snoring and heavy alcohol consumption. This is in accordance with some earlier reports $[6,8]$, but is in contrast to others [9]. The CAGE questionnaire used in this study has a high validity in measuring alcohol dependence. It is possible, however, that it does not correlate well with the amount of alcohol consumed.

All our results are based on answers to the questionnaires. We did not measure upper body mass, which might be an even more important confounder than BMI [19]. 
Possible over- and under-reporting may also affect the observed relationship between snoring and hypertension. There is no evidence, however, that snorers in general will be more inclined to give a false positive report on hypertension than nonsnorers. As snorers are more often smokers and overweight than nonsnorers, snoring seems to be an indication of "poor health behaviour", and it is possible that the willingness of snorers to participate in screening for hypertension is lower than that of nonsnorers. However, we cannot exclude the possibility that both snorers and their physicians are aware of the reports on health effects of snoring during recent years and are thus, more likely to request blood pressure measurements than nonsnoring subjects. The results are further biased by the fact that some of the subjects with "new hypertension" here were probably undiscovered hypertensives in 1984.

In the question relating to snoring, the subjects were asked to state how often they snored loudly and disturbingly. Despite the fact that no "don't know" alternative was given, the question was answered by $98.3 \%$ of the subjects. In the population investigated by Koskenvuo et al. [1], the prevalence of reported snoring was slightly lower among subjects living alone than among those living with a partner. There is also reason to assume that in our study, some of the subjects were not aware of their snoring status and that this might have led to an underestimation of the prevalence of snoring.

Snoring in 1984 was a significant predictor for both "new hypertension" and hypertension in 1994. In accordance with previous cross-sectional studies, this was true only for subjects below the age of 50 yrs [1, 3]. Even though the prevalence of persistent snoring was lower in the older age group, this does not explain the absence of an association between snoring and hypertension with increasing age. There are some data indicating that the respiratory effort due to increased upper airway resistance is more pronounced at younger ages [20]. The relationship between respiratory effort and cardiovascular effects, however, is not exactly known. Furthermore, it is possible that in the older age group the relative effects of risk factors other than snoring become greater. Another speculative possibility is that some people are more vulnerable to snoring, upper airway resistance and/or obstructive sleep apnoea syndrome (OSAS) in terms of vascular consequences, and develop their hypertension or cardiovascular disease earlier in life. Other subjects may, for some unknown reason, be less sensitive and can continue to be heavy snorers without side-effects on health.

In the reviews mentioned in the introduction $[12,13]$ it has been stated that it is unclear whether the association between snoring and hypertension is causal. Even though the results here indicate that snoring is important in the development of hypertension, our study cannot solve the central question of whether the relationship is causal. WALLER and BHOPAL [12] emphasized the lack of definition of snoring. There is still no standard and uniformly accepted technique for its objective measurement. Snoring habits do change over time and here we tried to consider that by dividing the population into four groups based not only on the snoring status at baseline, but also at the follow-up.

Snoring is a major symptom of OSAS and OSAS has been found to be significantly associated with hypertension in a dose-response fashion after adjustments for obesity, age and gender [21]. The association between snoring and hypertension in the present population might reflect a high prevalence of OSAS among a subgroup of the snorers [22]. The question has also been raised as to whether snoring, as a symptom of increased upper airway resistance, can be associated with hypertension even in the absence of apnoeas. As early as 1975 LUGARESI et al. [23] reported increased blood pressure during sleep among snorers and an association between the loudness of snoring and the magnitude of the inspiratory swings in intrathoracic pressure. Furthermore, in the polysomnographic study cited above, using $24 \mathrm{~h}$ ambulatory blood pressure monitoring, the variability of the blood pressure during sleep was significantly greater among participants who snored but without apnoeas than in nonapnoeic nonsnorers [21]. Whether and how snoring as a symptom of increased upper airway resistance can cause sustained daytime hypertension is, however, unclear.

We conclude that among men aged 30-49 yrs, reported snoring is a risk factor for developing hypertension over a $10 \mathrm{yr}$ period, independent of body mass index, weight gain and smoking habits. It also seems that this increased risk is independent of alcohol dependence and physical inactivity. To further analyse the question of whether snoring irrespective of apnoeas increases the risk of developing hypertension, large population-based prospective investigations with whole-night recordings, including objective measurements of snoring and apnoeas as well as blood pressure, are required.

\footnotetext{
Acknowledgement: The authors thank M. Medeen
} for excellent secretarial assistance.

\section{References}

1. Koskenvuo M, Kaprio J, Partinen M, Langinvainio H, Sarna S, Heikkila K. Snoring as a risk factor for hypertension and angina pectoris. Lancet 1985; 1: 893-896.

2. Mondini S, Zucconi M, Cirignotta F, et al. In: Guilleminault C, Lugaresi E, eds. Sleep/Wake Disorders: Natural History, Epidemiology and Long-Term Evolution. New York, Raven Press, 1983; pp. 99-105.

3. Gislason T, Åberg H, Taube A. Snoring and systemic hypertension: an epidemiological study. Acta Med Scand 1987; 221: 415-421.

4. Lugaresi E, Cirignotta F, Coccagna G, Piana C. Some epidemiological data on snoring and cardiocirculatory disturbances. Sleep 1980; 3: 221-224.

5. Bearpark H, Elliott L, Grunstein R, et al. Snoring and sleep apnea. A population study in Australian men. Am J Respir Crit Care Med 1995; 151: 1459-1465.

6. Schmidht-Nowara WW, Coultas DB, Wiggins C, Skipper BE, Samet JM. Snoring in a Hispanic-American population. Risk factors and association with hypertension and other morbidity. Arch Intern Med 1990; 150: 597-601

7. Wetter DW, Young TB, Bidwell TR, Badr MS, Palta M. Smoking as a risk factor for sleep-disordered breathing. Arch Intern Med 1994; 154: 2219-2224.

8. Bloom JW, Kaltenborn WT, Quan SF. Risk factors in a general population for snoring. Importance of cigarette smoking and obesity. Chest 1988; 93: 673-683.

9. Koskenvuo M, Partinen M, Kaprio J, et al. Snoring and cardiovascular risk factors. Ann Med 1994; 26: 371-376.

10. Stradling JR, Crosby JH. Relation between systemic hypertension and sleep hypoxaemia or snoring: analysis 
in 748 men from general practice. Br Med J 1990; 300: $75-78$.

11. Jennum P, Sjøl A. Snoring, sleep apnoea and cardiovascular risk factors: the MONICA II study. Int J Epidemiol 1993; 22: 439-444.

12. Waller PC, Bhopal RS. Is snoring a cause of vascular disease? An epidemiological review. Lancet 1989; 1: 143146.

13. Wright J, Johns R, Watt I, Melville A, Sheldon T. Health effects of obstructive sleep apnea and the effectiveness of continuous positive airway pressure: a systematic review of the research evidence. $\operatorname{Br}$ Med J 1997; 314: 851-860.

14. Gislason T, Almqvist M. Somatic diseases and sleep complaints - an epidemiological study of 3,201 Swedish men. Acta Med Scand 1987; 221: 475-481

15. Mayfield D, McLeod G, Hall P. The CAGE questionnaire: validation of a new alcoholism screening instrument. Am J Psychiatry 1974; 131: 1121-1123.

16. Beresford TP, Blow FC, Hill E, Singer K, Lucey MR. Comparison of CAGE questionnaire and computer-assisted laboratory profiles in screening for covert alcoholism. Lancet 1990; 336: 482-485.

17. Lissner L, Bengtsson C, Björkelund C, Wedel H. Physical activity levels and changes in relation to longevity. A prospective study of Swedish women. Am J Epidemiol 1996; 143: 54-62.

18. Ribacke M, Tibblin G, Rosengren A, Eriksson H. Is hypertension changing? Blood pressure development in cohorts of 50-year-old men between 1963 and 1993. Blood Press 1996; 5: 134-138.

19. Stradling JR, Crosby JH. Predictors and prevalence of obstructive sleep apnoea and snoring in 1001 middle aged men. Thorax 1991; 46: 85-90.

20. Krieger J, Sforza E, Boudewijns A, Zamagni M, Petiau C. Respiratory effort during obstructive sleep apnea: Role of age and sleep stage. Chest 1997; 112: 875-884.

21. Hla KM, Young TM, Bidwell T, Palta M, Skatrud JB, Dempsey J. Sleep apnea and hypertension. A population-based study. Ann Intern Med 1994; 120: 382-388.

22. Hoffstein V, Mateika S, Rubinstein I, Slutsky A S. Determinants of blood pressure in snorers. Lancet 1988; 2: 992-994.

23. Lugaresi E, Coccagna G, Farneti P, Mantovani M, Cirignotta F. Snoring. Electroceph Clin Neurophysiol 1975; 39: 59-64. 